\title{
Liquid-phase sintering of medical-grade P558 stainless steel using a new biocompatible eutectic additive
}

\author{
E. Salahinejad a,*, M.J. Hadianfard ${ }^{\text {a }}$, M. Ghaffari ${ }^{\text {b,c }}$, Sh. Bagheri Mashhadi ${ }^{\text {a }}$, A.K. Okyay ${ }^{\text {c }}$ \\ a Department of Materials Science and Engineering, School of Engineering, Shiraz University, Zand Blvd., 7134851154 Shiraz, Iran \\ ${ }^{b}$ School of Electrical and Electronic Engineering, Microelectronic Division, Nanyang Technological University, Nanyang Avenue, Singapore 639798, Singapore \\ c Department of Electrical and Electronics Engineering, UNAM-National Institute of Materials Science and Nanotechnology, Bilkent University, Ankara 06800, Turkey
}

\section{A R T I C L E I N F O}

\section{Article history:}

Received 7 November 2011

Accepted 26 January 2012

Available online 2 February 2012

\section{Keywords:}

Nanocrystalline materials

Microstructure

Sintering

\begin{abstract}
A B S T R A C T
One of the effective approaches to reduce residual pores in powder metallurgy parts is activated liquidphase sintering process using proper additives. In this work, for the first time, a new biocompatible additive (Mn-11.5 wt.\% Si, a eutectic alloy) is experimented for liquid-phase sintering of nanocrystalline/amorphous P558 stainless steel powders. It is realized that by increasing the sintering aid content and temperature, the density is effectively increased: a sharp densification progress when the sintering temperature increases from $1000{ }^{\circ} \mathrm{C}$ to $1050{ }^{\circ} \mathrm{C}$ and a slower densification rate when it exceeds $1050{ }^{\circ} \mathrm{C}$. This preliminary study opens up the development of high-density medical-grade stainless steels produced by powder metallurgy, where suitable additives can lower sintering temperature and time, which is promising for retarding grain growth and commercial applications.
\end{abstract}

(c) 2012 Elsevier B.V. All rights reserved.

\section{Introduction}

It is well established that residual pores in powder metallurgy parts are deleterious to mechanical properties and corrosion resistance [1]. To improve densification, a number of strategies including warm compaction, increasing sintering temperature and time, and using additives for liquid-phase sintering are under consideration. For liquid-phase sintering of stainless steels, various additives like $\mathrm{Cu}, \mathrm{Sn}, \mathrm{Ni}, \mathrm{Pt}, \mathrm{Ag}, \mathrm{Si}, \mathrm{Au}, \mathrm{B}, \mathrm{P}$, their compounds and alloys have been experimented $[1,2]$. The formation of a liquid phase activates the sintering process via providing a faster diffusion rate, particle rearrangement, pore elimination, and thereby improved densification [1-3]. It allows the commercial development of powder metallurgy parts further via decreasing sintering temperature and time.

In ASTM standards, two nickel-free medical grade stainless steels have been reported: ASTM F2228 (nominated as Biodur 108) and ASTM F2581 (nominated as P558). To our knowledge, no work has been reported on powder metallurgy, particularly liquid-phase sintering, of the latter so far. The use of a biocompatible additive in the process of sintering of medical-grade stainless steels is reasonable. In this work, for the first time, a new biocompatible sintering aid (Mn-11.5 wt.\% Si, a eutectic alloy) was tested to activate liquidphase sintering of nanocrystalline/amorphous P558 alloy powder synthesized by mechanical alloying.

\footnotetext{
* Corresponding author. Tel.: +98 917 3879390; fax: +98 7112307293.

E-mail address: erfan.salahinejad@gmail.com (E. Salahinejad).
}

\section{Experimental details}

P558 (Fe-17 Cr-10 Mn-3 Mo-0.4 Si-0.5 N-0.2 C, ASTM F2581) stainless steel powder as the main alloy and Mn-11.5 wt.\% Si eutectic alloy powder as the sintering aid were separately synthesized by mechanical alloying of $\mathrm{Fe}, \mathrm{Cr}, \mathrm{Mn}, \mathrm{Mo}, \mathrm{Si}$, and $\mathrm{C}$ (Merck) and iron nitride (Alfa Aesar) powders. Milling was conducted in a planetary ball mill under an argon atmosphere with a ball-to-powder weight ratio of $20: 1$ at a rotation speed of $500 \mathrm{rpm}$ for $48 \mathrm{~h}$ to make sure that the alloying process has been completed. Four bearing steel balls of $20-\mathrm{mm}$ and twelve bearing steel balls of $8-\mathrm{mm}$ diameters with a composition of Fe-1.5 Cr-0.9 C-0.8 Si-0.5 Mn were used in this study. Afterwards, the powders were milled in acetone for $1 \mathrm{~h}$. The obtained powders were characterized by a scanning electron microscope (SEM, JEOL-JSM 5310). In addition, the microstructure of the P558 powder was characterized by X-ray diffraction (XRD, Shimadzu Lab X-6000) and transmission electron microscope (TEM, FEI-Tecnai G2F30) methods.

The stainless steel powder was mixed with 3 and 6 wt.\% additive powder. In order to improve the homogeneity of the mixture and obtain finer particles with a narrow particle size distribution, the mixture was again milled in acetone for $1 \mathrm{~h}$, and dried at $70^{\circ} \mathrm{C}$, and finally annealed at $900{ }^{\circ} \mathrm{C}$ for $15 \mathrm{~min}$ to soften the hard milled powders and thereby to improve compactability prior to compaction. The obtained powders were pressed using a single acting press at a pressure of $1 \mathrm{GPa}$ without any lubrication. The densification process was followed by sintering at 1000,1050,1100, 1150, and $1200{ }^{\circ} \mathrm{C}$ for $90 \mathrm{~min}$ and then water-quenching to room temperature. 
Green and sintered densities were determined by weight and volume measurements and Archimedes water immersion method respectively. Moreover, the pore structures were observed by an optical microscope.

\section{Results and discussion}

Fig. 1a shows the SEM micrograph of the P558 powder milled in the dry condition and then in acetone, where the average size of the particles which are regular and relatively spherical in shape is almost $20 \mu \mathrm{m}$. The flattened and irregular morphology of the Mn-Si powder (Fig. 2b) can be justified by the ductile nature of the material and the lower applied milling time compared to the stainless steel powder. It is noteworthy that the size, size distribution, and morphology of the stainless steel powder are suitable for subsequent densification.
Acetone as a process control agent modifies the surface conditions of the powder particles via obstructing the clean metal-to-metal contacts required for cold welding. It results in a decrease in cold welding, alternatively an increase in fracturing, and thereby the development of finer particles [4]. During subsequent liquid-phase sintering, these powder particles with the regular shape and small size have a higher capillary stress, by which the particles are pulled together (particle rearrangement), leading to a faster densification [5]. The XRD pattern and TEM micrograph of the P558 stainless steel powder are provided in Fig. 1c and d. Comparing the XRD pattern of the initial powder mixture and milled powder signifies that mechanical activation introduced by milling is enough for the complete break-up and dissolution of the nitride and elements into the iron lattice (alloying process), where no characteristic peak of the constituent elements and nitride used was detected in the XRD
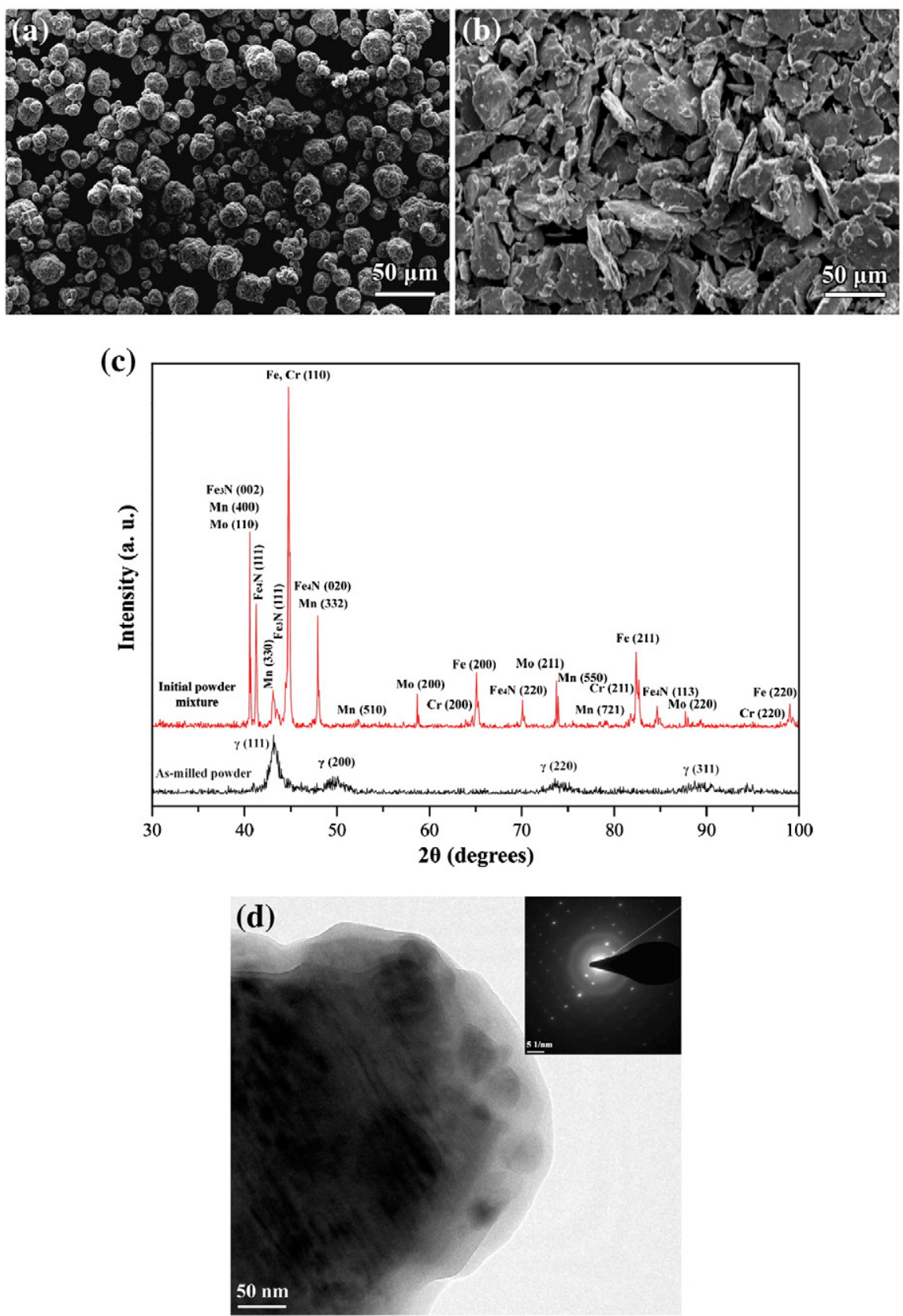

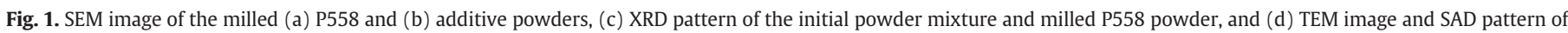
the milled P558 powder. 


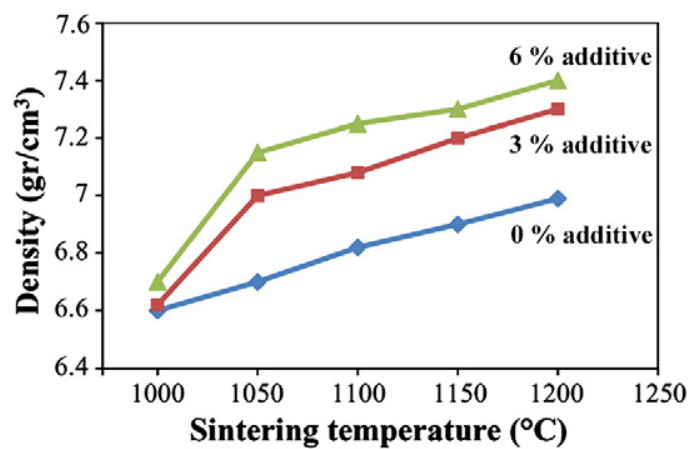

Fig. 2. Sintered densities measured by the Archimedes water immersion method.

data of the milled powder. According to Rietveld XRD quantitative analyses (detailed in Ref. [6]), the milled material consists of $10 \%$ ferrite $(\alpha), 48 \%$ austenite $(\gamma)$ and $42 \%$ an amorphous phase, where the crystallite size of the ferrite and austenite phases is 11.5 and

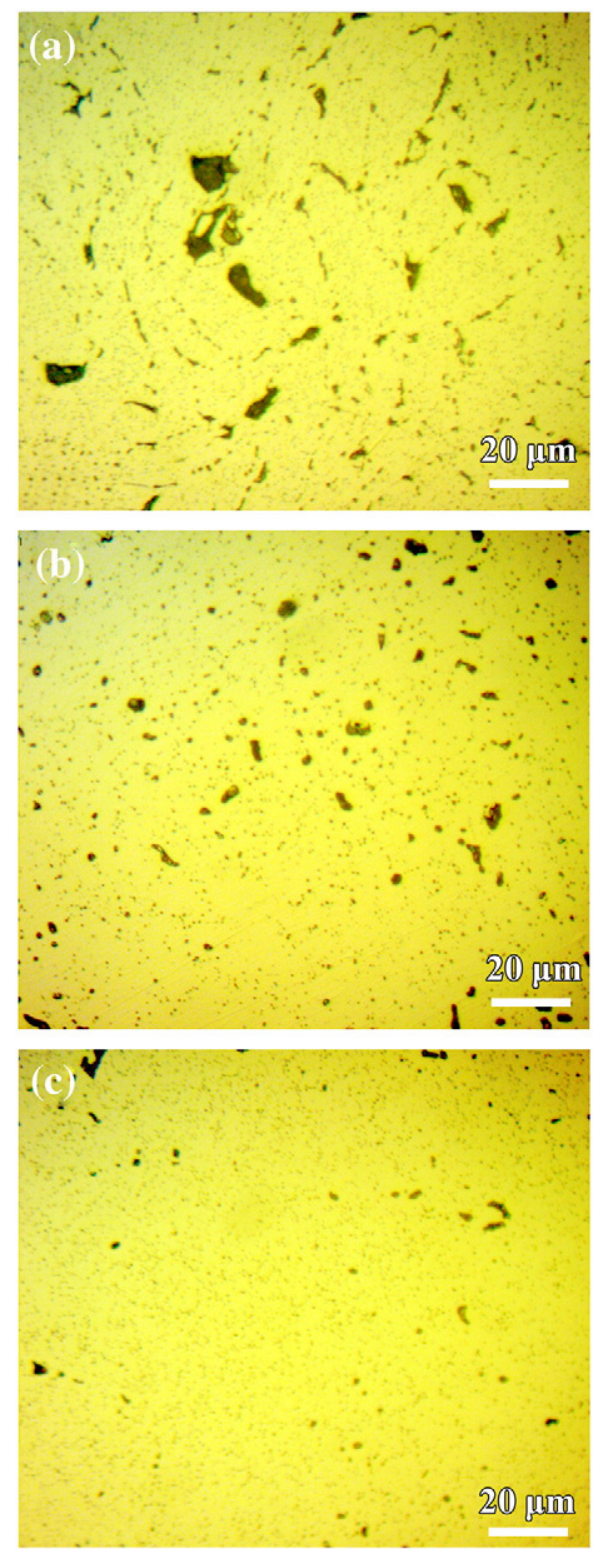

Fig. 3. Optical micrograph of the P558 samples containing 0 (a), 3 (b), and 6 (c) wt.\% additive sintered at $1150{ }^{\circ} \mathrm{C}$
$12 \mathrm{~nm}$ respectively. The selected area diffraction (SAD) pattern (the inset in Fig. 1d) includes some diffraction spots of the crystalline phases (related to the dark zones in the TEM image) and the halo pattern of the amorphous phase (related to the bright zones in the TEM image). Nanocrystallization and amorphization occurring during mechanical alloying are well explained in the literature [4,6,7].

From the weight and volume measurements, the green density of the samples containing 0,3 , and 6 wt.\% additive was measured to be $5.58,5.75$, and $5.83 \mathrm{~g} / \mathrm{cm}^{3}$ respectively. Considering the much near density of the additive and P558 alloys, the increase in the green density by increasing the additive content is attributed to a better compactability of the additive material caused by a lower hardness than the mechanically-alloyed stainless steel. Fig. 2 depicts the sintered densities measured by the Archimedes water immersion method. It can be generally seen that by increasing the additive content and sintering temperature, higher densities are achieved. For the stainless steel specimens ( $0 \%$ additive), a slow densification is observed because only slow solid-state sintering occurs. Nevertheless, for the samples containing the sintering aid, a sharp increase in density occurs when the sintering temperature increases from $1000{ }^{\circ} \mathrm{C}$ to $1050{ }^{\circ} \mathrm{C}$, followed by a lower rate densification with the further temperature increase.

The typical optical micrographs of the samples containing 0,3 , and $6 \mathrm{wt} . \%$ additive sintered at $1150{ }^{\circ} \mathrm{C}$ and those containing $6 \mathrm{wt} . \%$ additive sintered at the different temperatures are presented in Figs. 3 and 4 respectively. The micrographs signify a pore shrinkage and densification progress caused by enhanced sintering activation exerted with increasing the additive content and sintering temperature.

The additive ( $\mathrm{Mn}-11.5 \mathrm{wt} . \% \mathrm{Si}$ ) is a eutectic alloy with a eutectic temperature of $1040{ }^{\circ} \mathrm{C}$ [8]. Obviously, no liquation of this material occurs at temperatures less than the eutectic temperature, leading to a very small densification merely attributed to sluggish solidstate sintering for the samples sintered at $1000^{\circ} \mathrm{C}$. In contrast, the additive-containing samples sintered at the higher temperatures present more considerable densifications, as verified by the density measurements and optical observations (Figs. 2, 3, and 4). The formation of the eutectic liquid phase at the high temperatures activates the sintering process and contributes to higher rates of densification, accompanied with changes in pore morphologies towards smaller, spherical, and isolated pores. Indeed, the formed liquid at the additive particle sites wets the main powder particles, penetrates the particle contacts and pore zones via capillary forces, and provides a path of high diffusivity [1,2].

Focusing on the curve slope in Fig. 2 for the additive containing specimens, the considerable densification rate of the first temperature enhancement $\left(1000{ }^{\circ} \mathrm{C}\right.$ to $\left.1050{ }^{\circ} \mathrm{C}\right)$ compared to the lower rate of the subsequent temperature range $\left(1050{ }^{\circ} \mathrm{C}\right.$ to $\left.1200{ }^{\circ} \mathrm{C}\right)$ suggests that liquation which is responsible for considerable densification in the first range has a stronger impact on densification compared with sintering mechanisms governing at the temperatures greater than $1050^{\circ} \mathrm{C}$. With increasing the sintering temperature beyond $1050^{\circ} \mathrm{C}$, the decrease in the formed liquid viscosity, the increase in wetting characteristics, the increase in diffusivity, and possibly the increase in the liquid phase amount are responsible for densification, as reported for enhanced sintering of 304L stainless steel by silicon additions [9]. On the contrary, it was pointed out that sintering temperatures more than $1260{ }^{\circ} \mathrm{C}$ lead to no considerable densification of 17-4 PH stainless steel powder when $1 \mathrm{wt}$.\% nickel boride was used as additive [5].

\section{Conclusions}

Mn-11.5 wt.\% Si alloy was tested as a biocompatible eutectic additive for liquid-phase sintering of mechanically alloyed P558 stainless steel powders with a nanocrystalline/amorphous structure. From the density measurements and optical microscopy observations, 

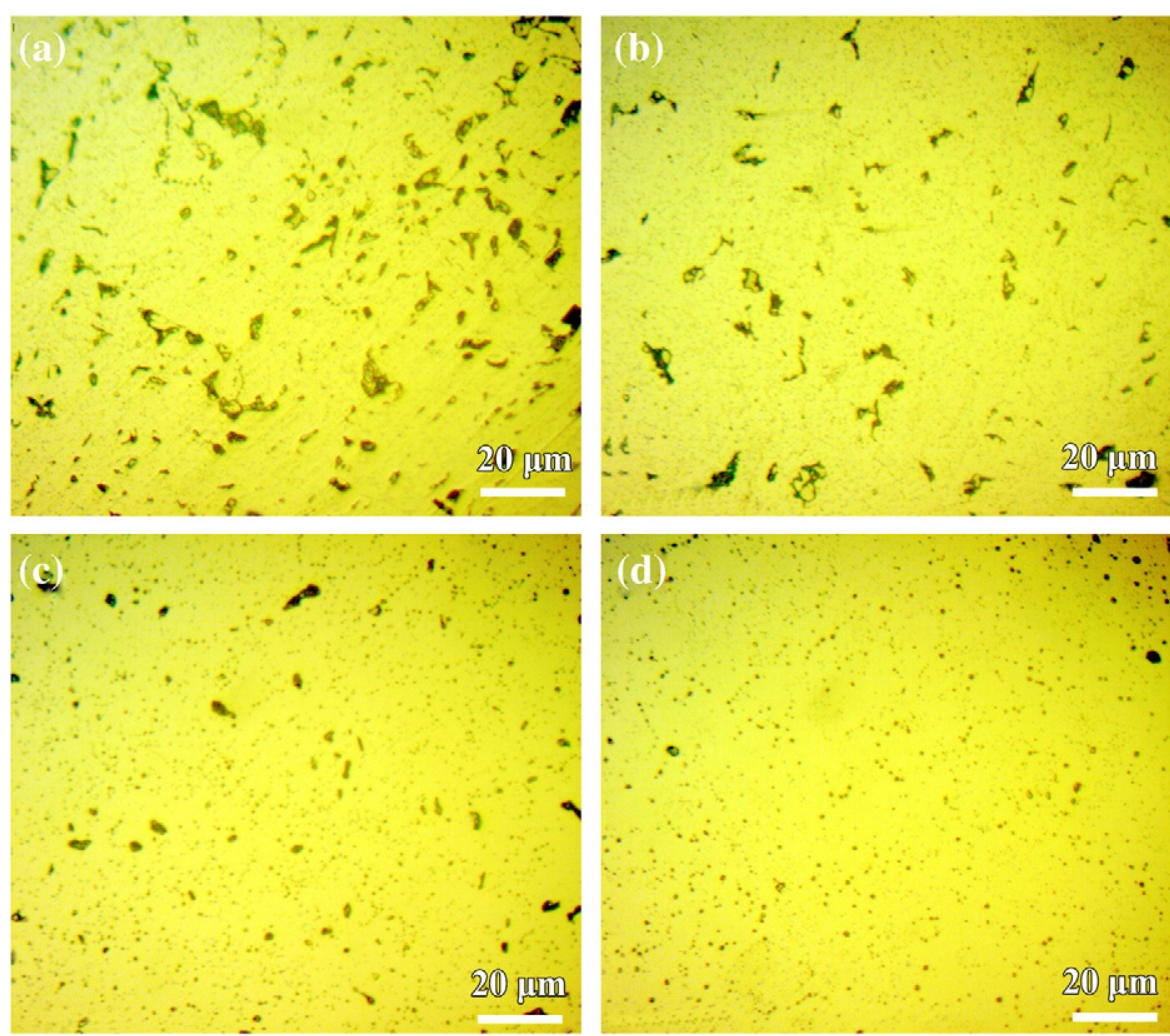

Fig. 4. Optical micrograph of the samples containing 6 wt.\% additive sintered at 1000 (a), 1050 (b), 1100 (c), and 1200 (d) ${ }^{\circ} \mathrm{C}$.

it is found that by increasing the additive content and sintering temperature, the density is increased. Considerable densities were achieved at sintering temperatures beyond $1050{ }^{\circ} \mathrm{C}$ where it is speculated that the eutectic fusion occurs.

\section{References}

[1] Klar E, Samal PK. Powder Metallurgy Stainless Steels: Processing, Microstructures, and Properties. ASM International; 2007. p. 59-100.
[2] German RM. Powder Metallurgy Science. 2nd ed. Metal Powder Industry Federation; 1994. p. 99-109.

[3] Youseffi M, Chong KY. Powder Metall 2003;46:30-8.

[4] Suryanarayana C. Prog Mater Sci 2001;46:1-184.

[5] Gulsoy HO. Scr Mater 2005;52:187-92.

[6] Amini R, Hadianfard MJ, Salahinejad E, Marasi M, Sritharan T. J Mater Sci 2009;44: $136-48$.

[7] Salahinejad E, Amini R, Hadianfard MJ. Powder Technol 2012;215-216:247-53.

[8] ASM HandbookAlloy Phase Diagrams, vol. 3. ASM International; 2003.

[9] Sharon A, Itzhak D. Mater Sci Eng A 1992;157:145-9. 